\title{
Comparison of Phytochemicals and Antioxidant Activity in Blackberry (Rubus fruticosus L.) Fruits of Mutant Lines at the Different Harvest Time
}

\author{
Jaihyunk Ryu', Soon-Jae Kwon ${ }^{1,2}$, Yeong Deuk Jo ${ }^{1}$, Chang Hyun Jin ${ }^{1}$, Bo Mi Nam¹, Seung Young Lee ${ }^{1,3}$, \\ Sang Wook Jeong ${ }^{1}$, Seung Bin $\mathrm{Im}^{1}$, Seung Cheol $\mathrm{Oh}^{4}$, Lan Cho ${ }^{4}$, Bo-Keun Ha ${ }^{5}$, Si-Yong Kang ${ }^{1 *}$ \\ ${ }^{1}$ Advanced Radiation Technology Institute, Korea Atomic Energy Research Institute, Jeongup 56212, Korea \\ ${ }^{2}$ Unversity of Science and Technology, Radiation Biotechnology and applied Radioisotope Science, Daejeon 34113, Korea \\ ${ }^{3}$ Nakdonggang National institute of Biological Resources, Sangju 37242, Korea \\ ${ }^{4}$ Bioplus Co., Wanju 55310, Korea \\ ${ }^{5}$ Division of Plant Biotechnology, College of Agriculture and Life Science, Chonnam National University, Gwangju 61186, Korea
}

\begin{abstract}
Blackberries (Rubus fruticosus L.) are a good source of antioxidants and contain appreciable levels of functional compounds. This study was carried out to evaluate fruit qualities ( $\mathrm{pH}$, soluble solids content, titratable acidity, and minerals), functional compounds (total phenolic content, total flavonoid content, anthocyanins, and ellagic acid), and antioxidant activity among five mutated blackberry lines over three ripening stages to examine the effect of fruit maturation on functional compounds and antioxidant activity. The content of sugars, total phenolic content, total flavonoid content, and anthocyanins (cyanidin-3-O-glucoside, cyanidin3-O-xyloside, cyanidin-3-O-malonylglucoside, and cyanidin-3-O-dioxalylglucoside) increased as fruit development advanced, whereas the ellagic acid content decreased as the fruit became more mature. Among the minerals tested, potassium showed the highest concentrations at all stages of development. The antioxidant activity was correlated with total phenolic content $(P \leq 0.01)$, total flavonoid content $(P \leq 0.01)$, and total anthocyanins $(P \leq 0.05)$. The results indicate that Maple and B201 lines contained the highest anthocyanin content and exhibited greater antioxidant activity.
\end{abstract}

Keywords Rubus fruticosus, Mutant lines, Functional compounds, Antioxidant activity

\section{INTRODUCTION}

Blackberries, fruit-bearing species of the genus Rubus of the Rosaceae family, are complex in terms of their genetic background, growth characteristics, and number of species (Clark et al. 2007; Ryu et al. 2014). Blackberries are used for the production of candy, dietary supplements, ice cream, jam, marmalade, and wine (Kaume et al. 2012).

In most fruits, the ripening process corresponds to a number of coordinated biochemical and physiological processes. Changes in some of the fruit components during the development process have been studied previously
(Prior et al. 1998; Wang and Lin 2000). However, little information is available regarding the antioxidant capacities in blackberry fruit at different developmental stages.

Berry fruits contain many different antioxidant components (Fan-Chiang and Wrolstad 2005; Brennan and Graham 2009). The phytochemicals in plants that are responsible for the antioxidant capacity can be attributed largely to secondary metabolites (Cho et al. 2004; Kim et al. 2013). Flavonoids are polyphenolic compounds that constitute a large group of secondary metabolites (Stack 1997; Cho et al. 2004; Lee et al. 2006). Anthocyanins are abundant flavonoids in blackberry fruit. The anthocyanins

Received April 12, 2016; Revised May 4, 2016; Accepted May 8, 2016; Published May 31, 2016

*Corresponding author Si-Yong Kang, sykang@kaeri.re.kr, Tel: +82-63-570-3310, Fax: +82-63-570-3319 
present in blackberries are important for beneficial health effects associated with their antioxidant, anti-inflammatory, and chemopreventative properties; the biological activity of blackberry against esophageal, colon, and oral cancers has been demonstrated (Skrede and Wrolstad 2002; Brennan and Graham 2009; Cho et al. 2014). In addition to anthocyanins, blackberry fruit is also a rich natural source of other chemopreventative phytochemicals such as flavonols, phenolic acids, and ellagic acid (Williner et al. 2003; Cuevas-Rodriguez et al. 2010). It is not uncommon for fruits or other plant material of related species to demonstrate varying degrees of biological activity ranging from totally inactive to exceptional activity (Wang and Lin 2000; Cho et al. 2004; Koca and Karadeniz 2009). Ellagic acid is the main phenolic compound in the berries of Rubus (Losso et al. 2004). Ellagic acid is a dietary hydroxybenzoic acid, which may occur in the free form in berries (Williner et al. 2003). Ellagic acid has shown antioxidative activity as an effective inhibitor of in vitro lipid peroxidation (Kim et al. 2013).

Mutation breeding is characterized by its merit, the creation of new mutant characteristics, and the addition of very few traits without disturbing other characteristics of a variety. Mutagenic agents, such as radiation and certain chemicals, can be used to induce mutations and generate genetic variations from which desired mutants may be selected. It offers the possibility of inducing desirable attributes that either cannot be found in nature or have been lost during evolution. In fruit crops, mutagenesis has already been used to introduce many useful traits affecting plant size, blooming time, fruit ripening, fruit color, self-compatibility, self-thinning, and resistance to pathogens (Visser et al. 1971; Donini 1982). Most of these traits continue to be worthy of introduction in many fruit species. The number of lines derived from mutation induction continues to increase.

The objective of this study was to investigate the physicochemical characteristics and antioxidant activity during fruit development (immature, intermediate, and ripened stages) in novel blackberry lines.

\section{MATERIALS AND METHODS}

\section{Plant materials and harvest}

Five blackberry lines were evaluated in this study. V-3 and V-9 are mother varieties. Maple and B201 mutant lines were derived from gamma-ray ( $80 \mathrm{~Gy}$ ) irradiation to tissue culture materials of V-3 and V-9, respectively. MNU32 was derived from a chemical mutagen, $N$-methyl- $N{ }^{\prime}$ nitrosourea (MNU) treatment to seeds of V9 (Table 1). Blackberry fruit was collected from a $3 \times 3 \mathrm{~m}^{2}$ quadrant. Three replicates were used for each sample. Fruit was harvested at three stages of maturity: immature, inter-

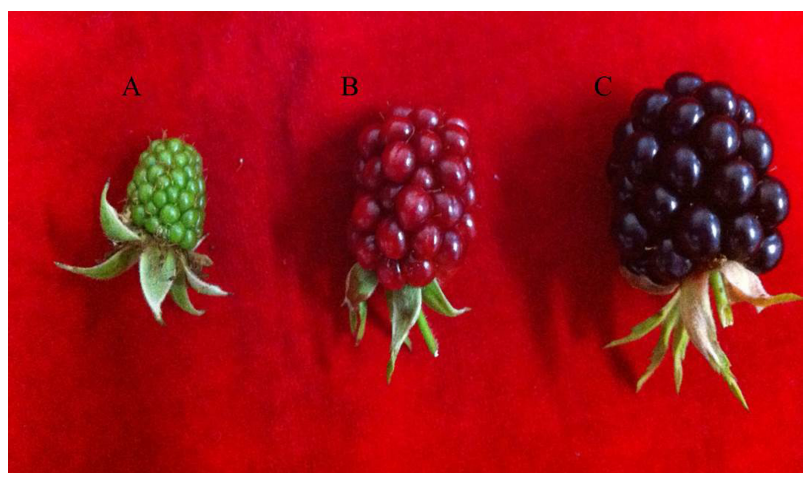

Fig. 1. Profile of fruit maturation stages. (A) Immature stage. (B) Intermediate. (C) Ripened stage.

Table 1. Origin of blackberry lines used in this study.

\begin{tabular}{lll}
\hline \hline Line & \multicolumn{1}{c}{ Orgin } & \multicolumn{1}{c}{ Mutagen type } \\
\hline V-3 & Super (New Zealand) & Somaclonal variation \\
Maple & V-3 & Gamma-ray 80 Gy $\left(10-1252077^{\mathrm{y})}\right)$ \\
V-9 & Super (New Zealand) & Somaclonal variation \\
B201 & V-9 & Gamma-ray 80 Gy $\left(2015-750^{\mathrm{x})}\right)$ \\
MNU-32 & V-9 & $N$-methyl- $N^{\prime}$-nitrosourea \\
\hline
\end{tabular}

${ }^{\mathrm{z})}$ V-3: Breeding line, V-9: Korea patent number, MNU-32: Korea seed and verity service application number. 
mediate, and ripened stages in 2015 (Fig. 1).

\section{Hydrogen exponent, soluble solids content and titratable acidity estimation}

Hydrogen exponent $(\mathrm{pH})$ was determined using a $\mathrm{pH}$ meter (Docu-pH meter; Sartorius Inc., Göttingen, Germany). Soluble solids content ( $\left({ }^{\circ} \mathrm{Brix}\right)$ was determined using a hand-held refractometer (Atago PR-101 $\alpha$; Atago USA Inc., Bellevue, WA, USA). The titratable acidity (\%) of the blackberry was determined by the AOAC (1995) method (AOAC International, Rockville, MD, USA).

\section{Mineral content}

We determined the mineral content using analytical methods. Samples $(1.0 \mathrm{~g})$ were weighed and subjected to dry ashing in a clean porcelain crucible at $550^{\circ} \mathrm{C}$ in a muffle furnace. The resultant ash was dissolved in $5.0 \mathrm{ml}$ of $\mathrm{HNO}_{3}$ : $\mathrm{HCl}: \mathrm{H}_{2} \mathrm{O}(1: 2: 3)$ and heated gently on a heating mantle until brown fumes disappeared. Then $5.0 \mathrm{ml}$ of distilled water was added to each sample in the crucible and heated until a colorless solution was obtained. The mineral solution was filtered into a $100-\mathrm{ml}$ volumetric flask. The solution was analyzed in triplicate for its elemental composition using a Perkin Elmer Model 403 (Perkin Elmer, Waltham, MA, USA) atomic absorption spectrophotometer.

\section{Total flavonoids and total phenolic content}

Total flavonoid content was measured using the aluminum chloride colorimetric method (Zhishen et al. 1999). An aliquot $(1 \mathrm{ml})$ of each extract was added to a 10 -ml volumetric flask containing $4 \mathrm{ml}$ of double-distilled water. We then added $0.3 \mathrm{ml}$ of $5 \% \mathrm{NaNO}_{2}$ to the flask, followed by $0.3 \mathrm{ml}$ of $10 \% \mathrm{AlCl}_{3} 5$ minutes later. After 6 minutes, $2 \mathrm{ml}$ of $\mathrm{NaOH}$ was added and the total volume was brought to $10 \mathrm{ml}$ with double-distilled water. The solution was mixed completely and the absorbance was measured at $510 \mathrm{~nm}$ and compared to that of the prepared reagent blank. The total flavonoid assay was performed three times for each extract. Standard curves were expressed as quercetin equivalents.

The amount of total phenolic content was determined using Folin-Ciocalteu reagent according to the method of
Slinkard and Singleton (1977). Briefly, $0.1 \mathrm{ml}$ of berry extract, $1.9 \mathrm{ml}$ of $\mathrm{H}_{2} \mathrm{O}$, and $2.5 \mathrm{ml}$ of Lowry $\mathrm{C}$ solution was mixed and allowed to stand for 10 minutes. Next, $0.25 \mathrm{ml}$ of Folin reagent was added followed by incubation for 30 minutes for stabilization of the blue color. The absorbance was measured at $750 \mathrm{~nm}$ against a blank. Total phenolic content was calculated from a standard curve of gallic acid; the results were expressed as milligram of gallic acid equivalents per $100 \mathrm{~g}$ of fresh weight.

\section{Anthocyanin extraction and high-performance liquid chromatography (HPLC) analysis}

The lyophilized, powdered fruits of blackberry were each extracted with $5 \mathrm{ml}$ of $0.05 \% \mathrm{HCl}$ in methanol for 2 hours at room temperature with periodic vortexing. All extracts were filtered immediately using a $0.45-\mu \mathrm{m}$ membrane filter prior to HPLC. Anthocyanins were analyzed using an HPLC system (CBM-20A; Shimadzu, Kyoto, Japan) with two gradient pumps (LC-30AD; Shimadzu), an ultraviolet (UV)-detector (SPD-M30A; Shimadzu), an auto sample injector, and a column oven. Separation was achieved on an HSS T3 column $(2.1 \times 100$ $\mathrm{mm}, 1.8 \mu \mathrm{m}$; Waters Inc., Milford, MA, USA) using a linear gradient elution program with a mobile phase containing solvent A and solvent $\mathrm{B}$. The anthocyanins were separated using the following gradients: 0-1 minutes, $10 \%$ B; 1-6 minutes, $10 \%-20 \%$ B; 6-8 minutes, $20 \%-95 \%$ B; 8-10 minutes, $5 \% \mathrm{~B}$. The anthocyanins were detected at $520 \mathrm{~nm}$ and identified using retention time, UV-visible spectral characteristics, and mass spectra (Stintzing et al. 2002; Dai et al. 2009).

\section{Ellagic acid analysis}

The lyophilized, powdered fruits of blackberry were diluted with purified water and methanol (37.5: 63.5); 10 $\mathrm{ml}$ of $1.2 \mathrm{~mol} / \mathrm{L} \mathrm{HCl}$ was then added. The mixture was refluxed for 16 hours at $80^{\circ} \mathrm{C} \pm 5^{\circ} \mathrm{C}$. The extract was allowed to cool and was then filtered through a $0.45-\mu \mathrm{m}$ membrane. The anthocyanins were separated using the following gradients: 0-3 minutes, 10\%-20\% B; 3-6 minutes, 20\%-30\% B; 6-9 minutes, 30\%-50\% B; 9-15 minutes, 50\%-60\% B; $15-18$ minutes, $60 \%-70 \% \mathrm{~B}$; $18-21$ minutes, $70 \%-50 \% \mathrm{~B}$; 21-24 minutes, $50 \%-30 \%$ B; $24-27$ minutes, $30 \%-0 \%$ B. 
Ellagic acid was detected at $254 \mathrm{~nm}$ and identified using commercial standards (Sigma, St. Louis, MO, USA).

\section{Determination of DPPH radical scavenging activity}

2,2-diphenyl-1-picrylhydrazyl (DPPH) radical scavenging activity was measured as described previously (Lee et al. 2006). Briefly, different concentrations of extract solutions were added to $0.15 \mathrm{mM}$ DPPH in ethanol, and the reaction mixture was shaken vigorously. The amount of remaining DPPH radicals was determined using a plate reader (Benchmark Plus; Bio-Rad, Hercules, CA, USA) at $517 \mathrm{~nm}$ after 30 minutes. The radical scavenging effect was calculated as follows:

$\mathrm{E}=[(\mathrm{Ac}-\mathrm{At}) / \mathrm{Ac}] \times 100$

At: absorbance values with samples

Ac: absorbance values without an extract solution

\section{Statistical analysis}

Analysis of variance (ANOVA) was performed using the multiple-comparisons method in the statistical package SPSS ver. 12 (SPSS Inc., Chicago, IL, USA). Correlation analysis was carried out to Pearson correlation coefficient. A $P$-value $<0.05$ indicated statistical significance. If a treatment effect was found to be significant, the means were differentiated using Duncan's multiple range tests.

\section{RESULTS}

\section{Hydrogen exponent, soluble solids content, and titratable acidity}

The hydrogen exponent, soluble solids content, and titratable acidity of blackberry fruits at different developmental stages are listed in Table 2. The hydrogen exponent value of blackberry fruits was significantly different among developmental stages. Hydrogen exponent values of all blackberry lines at the intermediate stage were lower than those of the other stages. Among the lines studied, the lowest hydrogen exponent at the ripened stage was observed with the MNU32 line. The measurement of soluble solids content was not possible at immature stage. The soluble solids content of all lines was 2.9-8.1 brix, and the value increased significantly with development. The MNU32 line had lower soluble solids content than other lines at the ripened stage. The titratable acidity was highest at the intermediate stage and it did not differ significantly

Table 2. Changes in hydrogen exponent, sugars content and titratable acidity of fruit development for blackberry lines.

\begin{tabular}{|c|c|c|c|c|c|c|c|c|c|}
\hline \multirow{2}{*}{ Line } & \multicolumn{3}{|c|}{ Hydrogen exponent } & \multicolumn{3}{|c|}{ Soluble solids content $\left({ }^{\circ}\right.$ Brix $)$} & \multicolumn{3}{|c|}{ Titratable acidity $(\%)$} \\
\hline & Immature & Intermediate & Ripened & Immature & Intermediate & Ripened & Immature & Intermediate & Ripened \\
\hline $\mathrm{V}-3$ & $4.1 \mathrm{a}^{\mathrm{z})}$ & $3.1 \mathrm{a}$ & $3.8 \mathrm{a}$ & $-\mathrm{y})$ & $3.4 \mathrm{c}$ & $8.0 \mathrm{a}$ & $1.4 \mathrm{c}$ & $3.2 \mathrm{a}$ & $1.7 \mathrm{c}$ \\
\hline Maple & $4.2 \mathrm{a}$ & $3.0 \mathrm{a}$ & $3.7 \mathrm{a}$ & - & $3.2 \mathrm{c}$ & $8.1 \mathrm{a}$ & $1.3 \mathrm{c}$ & $3.6 \mathrm{a}$ & $1.4 \mathrm{c}$ \\
\hline $\mathrm{V}-9$ & $4.1 \mathrm{a}$ & $2.9 \mathrm{a}$ & $3.7 \mathrm{a}$ & - & $2.9 \mathrm{c}$ & $8.0 \mathrm{a}$ & $1.5 \mathrm{c}$ & $3.4 \mathrm{a}$ & $1.4 \mathrm{c}$ \\
\hline B201 & $4.0 \mathrm{a}$ & $3.0 \mathrm{a}$ & $3.7 \mathrm{a}$ & - & $3.1 \mathrm{c}$ & $8.0 \mathrm{a}$ & $1.4 \mathrm{c}$ & $3.2 \mathrm{a}$ & $1.6 \mathrm{c}$ \\
\hline MNU32 & $4.1 \mathrm{a}$ & $3.1 \mathrm{a}$ & $3.4 \mathrm{~b}$ & - & $3.2 \mathrm{c}$ & $5.0 \mathrm{~b}$ & $1.6 \mathrm{c}$ & $3.6 \mathrm{a}$ & $2.4 \mathrm{~b}$ \\
\hline
\end{tabular}

${ }^{\mathrm{z})}$ The letters above each point indicate a significant difference at the $5 \%$ level (Duncan's multiple range tests).

${ }^{\mathrm{y})}$ Measurement was not possible.

Table 3. Mineral content of fruit development in blackberry lines $\left(\mathrm{mg} / 100 \mathrm{~g}^{-1}\right)$.

\begin{tabular}{|c|c|c|c|c|c|c|c|c|c|}
\hline \multirow{2}{*}{ Line } & \multicolumn{3}{|c|}{ Potassium } & \multicolumn{3}{|c|}{ Calcium } & \multicolumn{3}{|c|}{ Iron } \\
\hline & Immature & Intermediate & Ripened & Immature & Intermediate & Ripened & Immature & Intermediate & Ripened \\
\hline $\mathrm{V}-3$ & $14.2 b^{z)}$ & $16.5 \mathrm{a}$ & $12.5 \mathrm{c}$ & $9.2 \mathrm{~b}$ & $9.4 \mathrm{~b}$ & $12.6 \mathrm{a}$ & $1.3 \mathrm{~b}$ & $3.6 \mathrm{a}$ & $3.4 \mathrm{a}$ \\
\hline Maple & $15.0 \mathrm{~b}$ & $16.1 \mathrm{a}$ & $12.0 \mathrm{c}$ & $9.4 \mathrm{~b}$ & $9.4 \mathrm{~b}$ & $12.7 \mathrm{a}$ & $1.0 \mathrm{~b}$ & $3.4 \mathrm{a}$ & $3.8 \mathrm{a}$ \\
\hline V-9 & $14.6 \mathrm{~b}$ & $16.5 \mathrm{a}$ & $11.9 \mathrm{c}$ & $9.6 \mathrm{~b}$ & $9.6 \mathrm{~b}$ & $13.2 \mathrm{a}$ & $1.2 \mathrm{~b}$ & $3.4 \mathrm{a}$ & $3.4 \mathrm{a}$ \\
\hline B201 & $14.4 \mathrm{~b}$ & $16.4 \mathrm{a}$ & $12.3 \mathrm{c}$ & $9.4 \mathrm{~b}$ & $9.4 \mathrm{~b}$ & $12.5 \mathrm{a}$ & $1.1 \mathrm{~b}$ & $3.8 \mathrm{a}$ & $3.5 \mathrm{a}$ \\
\hline MNU32 & $14.5 b$ & $16.7 \mathrm{a}$ & $12.4 \mathrm{c}$ & $9.1 \mathrm{~b}$ & $9.4 \mathrm{~b}$ & $12.9 \mathrm{a}$ & $1.2 \mathrm{~b}$ & $3.8 \mathrm{a}$ & $3.4 \mathrm{a}$ \\
\hline
\end{tabular}

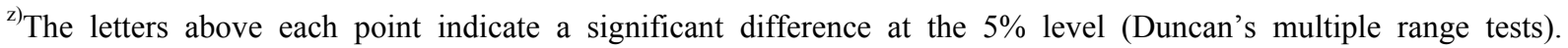


among the five lines at the immature and intermediate stages. The MNU32 line had higher titratable acidity compared with the other lines at the ripened stage.

\section{Mineral contents}

The mineral contents of the blackberry lines are presented in Table 3. Among the minerals monitored, potassium showed the highest concentrations during all three stages, with the intermediate stage being the highest. The calcium content was highest in the ripened stage and the iron content was lowest in the immature stage. Among the lines tested, the mineral contents did not differ significantly for all stages examined.

\section{Total phenolic and total flavonoid content}

The total phenolic and flavonoid contents of the fruit of the blackberry lines are shown in Fig. 2. The total phenolic (Fig. 2A) and total flavonoid content (Fig. 2B) differed significantly among development stages and lines. The total phenolic and total flavonoid content of all lines were $23.6-84.4 \mathrm{mg} / \mathrm{g}$ and $2.7-27.49 \mathrm{mg} / \mathrm{g}$, respectively. The total phenolic and total flavonoid content increased significantly as development advanced; the highest values were observed at the ripened stage. The highest total phenolic content recorded was for the Maple, V-9, and B201 lines and the V-3 line had the lowest content at the ripened stage. The
A

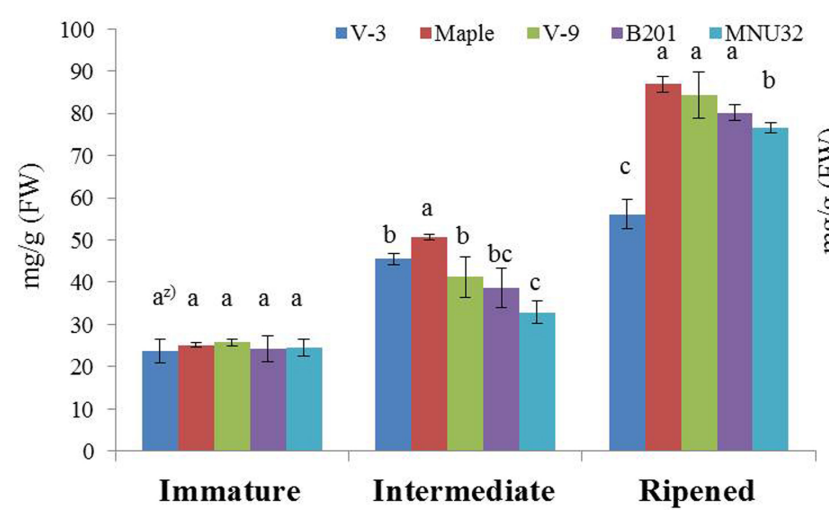

B

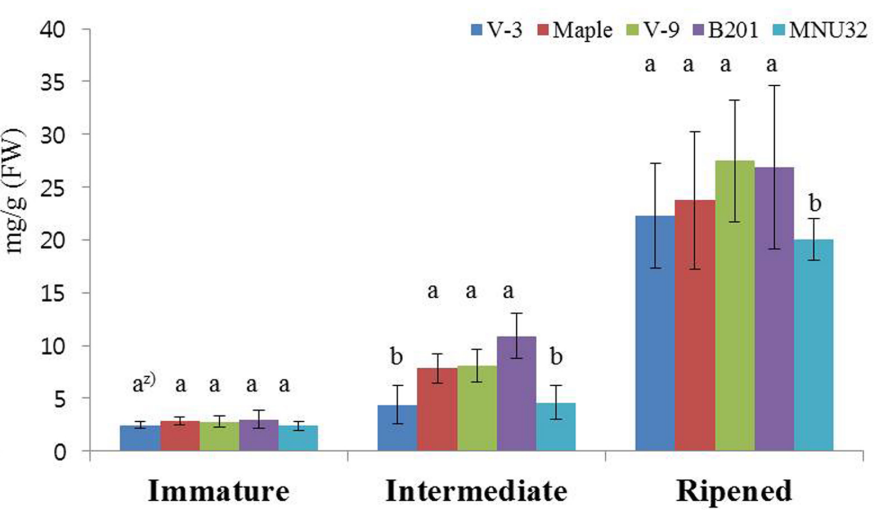

Fig. 2. Total phenolic content and total flavonoid content in novel blackberry lines. (A) Total phenolic content (mg/g). (B) Total flavonoid content $(\mathrm{mg} / \mathrm{g})$.

${ }^{\mathrm{z})}$ The letters above each point indicate a significant difference at the 5\% level (Duncan's multiple range tests). FW: fresh weight.
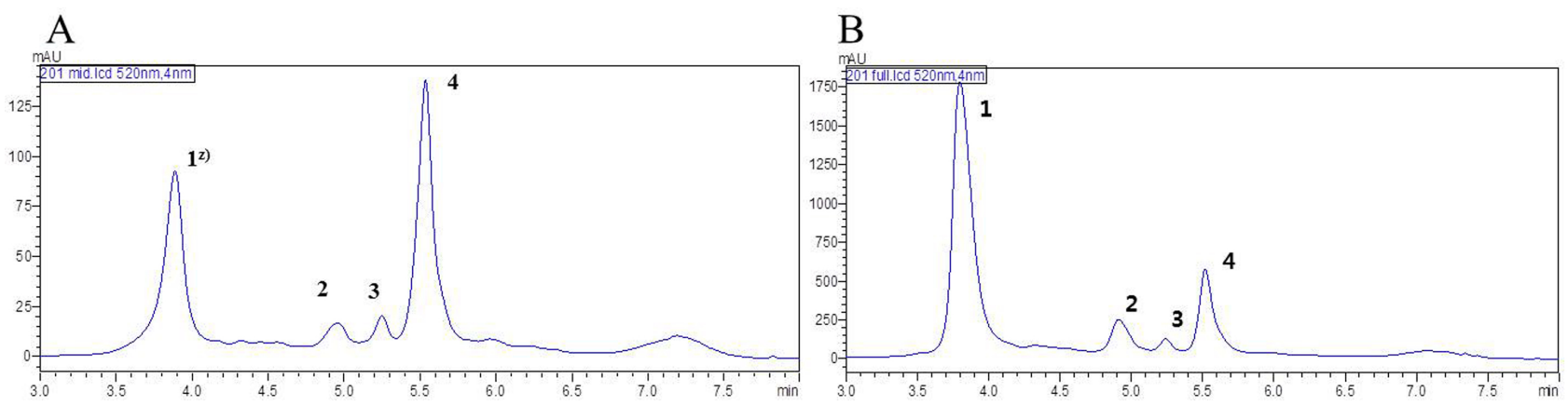

Fig. 3. High-performance liquid chromatography profiles of anthocyanin content in blackberry at different stages of development. (A) Intermediate stage. (B) Ripened stage.

${ }^{\text {Z) }}$ peak 1: cyanidin-3-O-glucoside, peak 2: cyanidin-3-O-xyloside, peak 3: cyanidin-3-O-malonylglucoside, Peak 4: cyanidin-3-O-dioxalylglucoside. 
Table 4. Changes in anthocyanin content of fruit development for blackberry lines.

\begin{tabular}{|c|c|c|c|c|c|c|c|c|c|c|}
\hline \multirow{2}{*}{ Lines } & \multicolumn{2}{|c|}{ Cy-3-Glu ${ }^{\text {z) }}$} & \multicolumn{2}{|c|}{ Cy-3-Xyl } & \multicolumn{2}{|c|}{ Cy-3-Mglu } & \multicolumn{2}{|c|}{ Cy-3-Dioxglu } & \multicolumn{2}{|c|}{$\mathrm{ACN}$} \\
\hline & Intermediate & Ripened & Intermediate & Ripened & Intermediate & Ripened & Intermediate & Ripened & Intermediate & Ripened \\
\hline$V-3$ & $18.7 \mathrm{~d}^{\mathrm{y})}$ & $191 b$ & $3.3 \mathrm{~d}$ & $29.3 b$ & $3.5 \mathrm{c}$ & $10.0 \mathrm{~b}$ & $25.6 \mathrm{~d}$ & $36.0 \mathrm{~b}$ & $57.5 \mathrm{~d}$ & $314.0 \mathrm{~b}$ \\
\hline Mayple & $17.7 \mathrm{~d}$ & $320 \mathrm{a}$ & $3.2 \mathrm{~d}$ & $44.8 \mathrm{a}$ & $3.3 \mathrm{c}$ & $20.2 \mathrm{a}$ & $24.2 \mathrm{~d}$ & $101.6 \mathrm{a}$ & $55.2 \mathrm{~d}$ & $537.7 \mathrm{a}$ \\
\hline V-9 & $7.4 \mathrm{e}$ & $187 \mathrm{~b}$ & $2.0 \mathrm{e}$ & $30.0 \mathrm{~b}$ & $1.7 \mathrm{~d}$ & $9.9 \mathrm{~b}$ & $14.2 \mathrm{e}$ & $36.7 \mathrm{~b}$ & $30.7 \mathrm{e}$ & $327.5 b$ \\
\hline B201 & $18.2 \mathrm{~d}$ & $335.6 \mathrm{a}$ & $3.2 \mathrm{~d}$ & $47.1 \mathrm{a}$ & $3.4 \mathrm{c}$ & $20.9 a$ & $24.8 \mathrm{~d}$ & $107.5 \mathrm{a}$ & $58.7 \mathrm{~d}$ & $558.2 \mathrm{a}$ \\
\hline MNU32 & $7.5 \mathrm{e}$ & $92.3 \mathrm{c}$ & $2.0 \mathrm{e}$ & $12.1 \mathrm{c}$ & $1.8 \mathrm{~d}$ & $5.7 b$ & $14.6 \mathrm{e}$ & $16.9 \mathrm{c}$ & $31.5 \mathrm{e}$ & $191.6 \mathrm{c}$ \\
\hline
\end{tabular}

${ }^{z} \mathrm{Cy} 3$ glu: cyanidin-3-O-glucoside, Cy3xyl: cyanidin-3-O-xyloside, Cy3Mglu: cyanidin-3-O-malonylglucoside, Cy3Dioxglu: cyanidin-3-O-dioxalylglucoside, ACN: individual compounds presented as percentage of total peak area monitored at 520 nm.

${ }^{\mathrm{y})}$ The letters above each point indicate a significant difference at the $5 \%$ level (Duncan's multiple range tests).

MNU32 line had lower total flavonoid content than other lines at the ripened stage.

\section{Anthocyanin content}

The HPLC chromatograms of blackberry fruit revealed the presence of four peaks at the intermediate and ripened stages (Supplement Table 1; Fig. 3). Four anthocyanins, cyanidin-3-O-glucoside (Fig. 3A, B peak 1 ) cyanidin-3-Oxyloside (Fig. 3A, B peak 2), cyanidin-3-O-malonylglucoside (Fig. 3A, B peak 3, C-3), cyanidin-3-O-dioxalylglucoside (Fig. 3A, B peak 4) were isolated.

There were significant differences in anthocyanin contents among lines and development stages (Table 4). Anthocyanin pigments were not detectable until the fruit reached the intermediate stage. The highest anthocyanin levels were observed at the ripened stage for all lines tested. Among anthocyanins, cyanidin-3-O-dioxalylglucoside showed the highest content in all blackberry lines in the intermediate stage, followed by cyanidin-3-O-glucoside $>$ cyanidin-3-O-xyloside > cyanidin-3- $O$-malonylglucoside (Fig. 3B). The total anthocyanin content (ACN) ranged from $30.7 \mathrm{mg} / 100 \mathrm{~g}$ (V-9) to $58.7 \mathrm{mg} / 100 \mathrm{~g}$ at the ripened stage. V-3, Maple, and B201 lines showed higher levels of all anthocyanin pigments than did the V-9 and MNU32 line at the ripened stage (Supplement Fig. 1). Cyanidin-3-Oglucoside was the major pigment in all blackberry lines at the ripened stage (Fig. 3A). Cyanidin-3-O-xyloside, cyanidin-3-O-malonylglucoside, and cyanidin-3-O-dioxalylglucoside contents were minor components of the blackberry fruit at the ripened stage. The cyanidin-3-O-
Table 5. Ellagic acid content in blackberry lines at different ripening stage.

\begin{tabular}{lccc}
\hline \hline \multirow{2}{*}{ Line } & \multicolumn{3}{c}{ Ellagic acid $(\mathrm{mg} / 100 \mathrm{~g})$} \\
\cline { 2 - 4 } & Immature & Intermediate & Ripened \\
\hline V-3 & $80.1 \mathrm{a}^{\mathrm{z}}$ & $50.0 \mathrm{c}$ & $47.0 \mathrm{c}$ \\
Maple & $81.5 \mathrm{a}$ & $40.1 \mathrm{~d}$ & $35.2 \mathrm{e}$ \\
V-9 & $80.6 \mathrm{a}$ & $51.5 \mathrm{c}$ & $28.8 \mathrm{f}$ \\
B201 & $78.6 \mathrm{a}$ & $54.3 \mathrm{c}$ & $42.5 \mathrm{~d}$ \\
MNU32 & $82.3 \mathrm{a}$ & $65.1 \mathrm{~b}$ & $41.8 \mathrm{~d}$ \\
\hline
\end{tabular}

${ }^{2)}$ The letters above each point indicate a significant difference at the 5\% level (Duncan's multiple range tests).

glucoside content of blackberry at the ripened stage ranged from 92.3 to $335.6 \mathrm{mg} / 100 \mathrm{~g}$. Among the lines, B201 had the highest level $(335.6 \mathrm{mg} / 100 \mathrm{~g})$ of cyanidin-3-O-glucoside at the ripened stage, followed by Maple $(320.2 \mathrm{mg} / 100$ g) > V-3 $(191.0 \mathrm{mg} / 100 \mathrm{~g}) \geq \mathrm{V}-9(187.2 \mathrm{mg} / 100 \mathrm{~g})>$ MNU32 $(92.3 \mathrm{mg} / 100 \mathrm{~g})$ in descending order (Supplement Fig. 2). Maple and B201 lines had higher ACN compared with the other lines at the ripened stage. The $\mathrm{ACN}$ ranged from 191.6 to $558.2 \mathrm{mg} / 100 \mathrm{~g}$, with a mean of 385.8 $\mathrm{mg} / 100 \mathrm{~g}$ at the ripened stage.

\section{Ellagic acid content}

The ellagic acid levels of all lines ranged 28.8-82.3 $\mathrm{mg} / 100 \mathrm{~g}$, and the value declined significantly as development advanced; the highest values were observed during the immature stage (Table 5). Ellagic acid contents were significant differences among lines and development stages. Ellagic contents decreased as the fruit became more mature, but the V-3 line showed no significant differences 


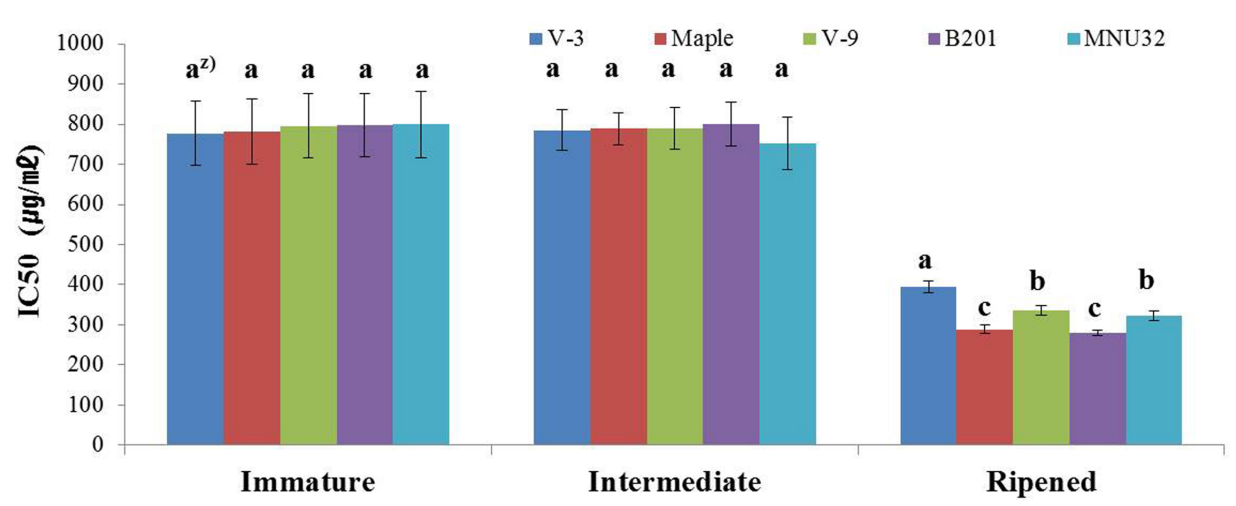

Fig. 4. 2,2-diphenyl-1-picrylhydrazyl radical scavenging activities of novel blackberry lines at different stages of development. ${ }^{z)}$ The letters above each point indicate a significant difference at the $5 \%$ level (Duncan's multiple range tests).

in ellagic acid content between the intermediate and ripened stages. There were no significant differences in ellagic acid content among the lines at the immature stage. MNU32 had the highest amount $(65.1 \mathrm{mg} / 100 \mathrm{~g})$ of ellagic acid at the intermediate stage, followed by B201 (54.3 $\mathrm{mg} / 100 \mathrm{~g}) \geq \mathrm{V}-9(51.5 \mathrm{mg} / 100 \mathrm{~g}) \geq \mathrm{V}-3(50.0 \mathrm{mg} / 100 \mathrm{~g})$ $>$ Maple $(40.1 \mathrm{mg} / 100 \mathrm{~g})$. The ellagic acid content at the ripened stage ranged from $28.8-47.0 \mathrm{mg} / 100 \mathrm{~g}$, with a mean of $38.0 \mathrm{mg} / 100 \mathrm{~g}$. The V-9 line had lower ellagic acid content than other lines at the ripened stage.

\section{DPPH radical scavenging activity}

The DPPH radical scavenging activity for each blackberry line at different development stages are shown in Fig. 4. The DPPH radical scavenging activity of all blackberry lines increased as fruits became more mature; Maple and B201 showed the highest DPPH radical scavenging activities at the ripened stage. There were no significant differences in DPPH radical scavenging activity between the intermediate and immature stages for all lines (Fig. 4).

\section{DISCUSSION}

Blackberries are a new crop to many areas of the world. Traditionally, Rubus species have been used in East Asia as a therapeutic medicine for inflammatory diseases such as atherosclerosis (Ferreira et al. 2011; Kim et al. 2013).
Blackberries are less expensive to produce than raspberries and Rubus coreanus because they do not need to be replanted as often, they are convenient for pruning, and produce a higher fruit yield (Clark et al. 2007; Brennan and Graham 2009).

Radiation mutation breeding combined with in-vitro culture has made a significant contribution to plant breeding. The Maple line, obtained from gamma-ray mutation, has fruit characteristics such as bigger size, higher disease resistance, and higher cyanidin-3-O-glucoside content compared with other lines (Kim and Yoon 2013). The B201 line, also derived from gamma-ray mutation, has fruit characteristics such as early maturation, higher disease resistance, and higher cyanidin-3-O-glucoside content, compared with other lines (Cho et al. 2014). Cho et al. (2014) reported in-vitro results demonstrating that B201 extract increased cell viability, reduced lactate dehydrogenase release, and increased intracellular reactive oxygen species scavenging capacity in hydrogen peroxide $\left(\mathrm{H}_{2} \mathrm{O}_{2}\right)$ treated HepG2 cells. Furthermore, treatment with B201 attenuated DNA damage and restored the activity of superoxide dismutase and catalase in $\mathrm{H}_{2} \mathrm{O}_{2}$-treated $\mathrm{HepG} 2$ cells.

During ripening, the chemical characteristics and antioxidant activity for blackberries lines were evaluated. The soluble solids content of blackberries increased significantly as fruits developed. Soluble solids content can vary with different growth conditions; however, there was no change in trend, even for different growth conditions 
and lines (Ryu et al. 2012). The titratable acidity content is an important quality attribute, especially for berries (Vrhovsek et al. 2008). Acidity was inversely correlated with the hydrogen exponent. The intermediate stage, which had high titratable acidity content, had a correspondingly low hydrogen exponent. Abundant mineral content, such as potassium, calcium, and iron, have been reported for blackberry; especially, potassium was the most abundant mineral in blackberry fruits (Guedes et al. 2013). Davies et al. (2006) reported that decreasing titratable acidity with the enhancement of potassium levels could be due to interactions with tartaric acid to form potassium tartrate, which has limited solubility. Our results are consistent with those of Davies et al. (2006).

Rubus species contain high levels of polyphenolic compounds in the fruit, including flavonoids, such as anthocyanins and flavonols (Brennan and Graham 2009; Cuevas-Rodriguez et al. 2010). The anthocyanin content of blackberries compares favorably with other fruits (Skrede and Wrolstad 2002). Our results showed that anthocyanin contents were enriched dramatically in the ripened stage. These findings are similar to the total anthocyanin content observed by Chen et al. (2012). Our results were attributed to the influence of fruit development on anthocyanin composition. Cyanidin-3-O-dioxalylglucoside was the most abundant anthocyanin at the intermediate stage, whereas cyanidin-3-O-glucoside was the most abundant anthocyanin at the ripened stage. Cyanidin-3-glucoside has long been established as the major anthocyanin in blackberries at the ripened stage (Stintzing et al. 2002). Dai et al. (2009) described the presence of cyanidin-3-xyloside along with two cyanidin derivatives that were vaguely characterized as being substituted with dicarboxylic acids. Cyanidin-3-O-malonylglucoside and cyanidin-3-O-dioxalylglucoside have been identified from $R$. glaucus and $R$. adenotrichus (Mertz et al. 2007). Interestingly, a previous report showed that cyanidin-3-O-malonylglucoside and cyanidin-3-O-dioxalylglucoside contents may be affected by environmental stresses (Kang and Lee 2011).

The ACN of V-3, Maple, V-9, and B201 lines at the ripened stage were higher than those recorded by Fan-Chiang and Wrolstad (2005), who reported values of 70.3 to $201 \mathrm{mg} / 100 \mathrm{~g}$ for 51 blackberry cultivars.
Table 6. Correlation analysis between chemical content and antioxidant activity in blackberry fruit.

\begin{tabular}{lcc}
\hline \multicolumn{1}{c}{ Trait } & $\mathrm{p}$-value & $\mathrm{R}^{2}$ \\
\hline Total phenolic content & $* *$ & 0.716 \\
Total flavonoid content & $* *$ & 0.647 \\
Cyanidin-3- $O$-malonylglucoside & $*$ & 0.552 \\
Cyanidin-3- $O$-dioxalylglucoside & $*$ & 0.562 \\
Total anthocyanin $\left(\mathrm{ACN}^{\mathrm{z})}\right)$ & $*$ & 0.530 \\
\hline
\end{tabular}

*: $P \leq 0.05, * *: P \leq 0.01$.

${ }^{\mathrm{z})} \mathrm{ACN}$ : individual compounds presented as percentage of total peak area monitored at $520 \mathrm{~nm}$.

Ellagic acid is a hydrolytic product of ellagitannins, which occur naturally in many plant species of economic importance, especially berry fruits (Williner et al. 2003; Losso et al. 2004). Ellagic acid is a well-identified bioactive component that regulates oxidized low-density lipoprotein uptake and cholesterol efflux in murine macrophages and inhibits NF-KB-mediated inflammation (Lee et al. 2010). This study, the green fruit stage has been found to contain twice as much ellagic acid as the red fruit stage for all lines. The ellagic acid contents at different fruit development stages were similar to those reported by Williner et al. (2003) for strawberry grown in Argentina.

The Pearson's correlation coefficients (based on average quantified values of chemical data and DPPH radical scavenging activity) are listed in Table 6 . The antioxidant activity was positively correlated with total phenolic content $(P \leq 0.01)$, total flavonoid content $(P \leq 0.01)$, cyanidin-3- $O$-malonylglucoside $(P \leq 0.05)$, cyanidin-3- $O$ dioxalylglucoside $(P \leq 0.05)$, and total anthocyanins $(P \leq$ 0.05). Similarly, Wang and Lin (2000) reported that the antioxidant activity of blackberries is highly correlated with anthocyanin pigment content. Strong correlations between antioxidant activity and total flavonoid or total phenolic contents have also been reported in various studies on berry fruits (Wang and Lin 2000; Cho et al. 2004; Lee et al. 2006; Cho et al. 2014).

The use of blackberries as a source of antioxidant activity and functional components may provide an opportunity for increased blackberry consumption. In addition, breeding for high anthocyanin content of fruits should be highly successful. Our results suggest that Maple 
and B201 are the most appropriate materials for health food because they contained higher anthocyanin contents and exhibited greater antioxidant activities.

\section{ACKNOWLEDGEMENTS}

This work was supported by Korea institute of planning and evaluation for technology in food, agriculture, forestry and Fisheries (IPET) through (Mutation breeding and industrialization through radiation mutation breeding research) funded by Ministry of Agriculture, Food and Rural Affairs and Nuclear R\&D Program by the Ministry of Science, ICT and Future Planning (MSIP; 2012M2A2A6003), Republic of Korea

\section{REFERENCES}

AOAC International. 1995. Official methods of analyses of AOAC international. 16th ed. AOAC International, Rockville, MD.

Brennan R, Graham J. 2009. Improving fruit quality in Rubus and Ribes through breeding. Funct. Plant Sci. Biotech. 23-29.

Chen Q, Zhang XN, Yu HW, Wang Y, Tang HR. 2012. Changes of total anthocyanins and proanthocyanidins in the developing blackberry fruits. Int. J. Chem. Tech. Res. 4: 129-137.

Cho BO, Lee CW, So YK, Jin CH, Yook HS, Byun MW, et al. 2014. Protective effect of radiation-induced new blackberry mutant $\gamma$-B201 on $\mathrm{H}_{2} \mathrm{O}_{2}$-induced oxidative damage in HepG2 cells. Korean J. Food Sci. Technol. 46: 384-389.

Cho MJ, Howard LR, Prior RL, Clark JR. 2004. Flavonoid glycosides and antioxidant capacity of various blackberry, blueberry and red grape genotypes determined by high-performance liquid chromatography/ mass spectrometry. J Sci. Food Agric. 84: 1771-1782.

Clark JR. Stafne ET, Hall HK, Finn CE. 2007. Blackberry breeding and Genetics, p.19-53. In: J. Janick (ed.). Plant breeding reviews. John Wiley and Sons Inc., New York, NY.

Cuevas-Rodriguez EO, Yousef GG, Garcia-Saucedo PA,
Lopez-Medina J, Paredes-Lopez O, Lila MA. 2010. Characterization of anthocyanins and proanthocyanidins in wild and domesticated Mexican blackberries (Rubus spp.). J. Agric. Food Chem. 58: 7458-7464.

Dai J, Gupte A, Gates L, Mumper RJ. 2009. A comprehensive study of anthocyanin-containing extracts from selected blackberry cultivars: extraction methods, stability, anticancer properties and mechanisms. Food Chem. Toxicol. 47: 837-847.

Davies C, Shin R Liu W, Thomas MR, Schachtman DP. 2006. Transpoters expressed during grape berry (Vitis vinifera L.) development are associated with an increase in berry size and berry potassium accumulation. J. Exp. Bot. 57: 3209-3216.

Donini B. 1982. Mutagenesis applied to improve fruit trees: techniques, methods and evaluation or radiation induced mutations, p.29-36. In: IAEA (ed.). Induced mutations in vegetatively propageted plants II. IAEA, Vienna, Austria.

Fan-Chiang HJ, Wrolstad RE. 2005. Anthocyanin pigment composition of blackberries. J. Food Sci. 70: C198-C202.

Ferreira de Araujo PR, da Silva SV, Rodrigues MA, Gevehr FC, Silva JA, da Silva RR. 2011. Benefits of blackberry nectar (Rubus spp.) relative to hypercholesterolemia and lipid peroxidation. Nutr. Hosp. 26: 984-990.

Guedes MNS, Abreu CMP, Maro LAC, Pio R, Abreu JR, Oliverira JO. 2013. Chemical characterization and mineral levels in the fruits of blackberry cultivars grown in a tropical climate at an elevation. Acta Sci. Agron. 35: 191-196.

Kang NS, Lee JH. 2011. Characterisation of phenolic phytochemicals and quality changes related to the harvest times from the leaves of Korean purple perilla (Perilla frutescens). Food Chem. 124: 556-562.

Kaume L, Howard LR, Devareddy L. 2012. The blackberry fruit: a review on its composition and chemistry, metabolism and bioavailability, and health benefits. J. Agr. Food Chem. 60: 5716-5727.

Kim EY, Yoon TY, Jo HJ, Yoo YR. inventor; Koreanstevia Inc., assignee. 2013 Apr 12. Korea patent 10-1252077.

Kim S, Kim CK, Lee KS, Kim JH, Hwang H, Jeoung D, et al. 2013. Aqueous extract of unripe Rubus coreanus fruit attenuates atherosclerosis by improving blood lipid profile and inhibiting NF-kB activation via phase II gene expression. J. Ethnopharmacol. 146: 515-524.

Koca I, Karadeniz B. 2009. Antioxidant properties of 
blackberry and blueberry fruits grown in the black sea region of Turkey. Sci. Hortic. 121: 447-450.

Lee BW, Lee JH, Gal SW, Moon YH, Park KH. 2006. Selective ABTS radical-scavenging activity of prenylated flavonoids from Cudrania tricuspidata. Biosci. Biotech. Bioch. 70: 427-432.

Lee WJ, Ou HC, Hsu WC, Chou MM, Tseng JJ, Hsu SL, et al. 2010. Ellagic acid inhibits oxidized LDL-mediated LOX-1 expression, ROS generation, and inflammation in human endothelial cells. J. Vasc. Surg. 52: 1290-1300.

Losso JN, Bansode RR, Trappey A, Bawadi HA, Truax R. 2004. In vitro anti-proliferative activities of ellagic acid. J. Nutr. Biochem. 15: 672-678.

Mertz C, Cheynier V, Günata Z, Brat P. 2007. Analysis of phenolic compounds in two blackberry species (Rubus glaucus and Rubus adenotrichus) by high-performance liquid chromatography with diode array detection and electrospray ion trap mass spectrometry. J. Agri. Food Chem. 55: 8616-8624.

Prior RL, Cao G, Martin A, Sofic E, McEwen J, O’Brien C, et al. 1998. Antioxidant capacity as influenced by total phenolic and anthocyanin content, maturity, and variety of vaccinium species. J. Agric. Food Chem. 46: 2686-2693.

Ryu J, Ha BK, Kim DS, Kim JB, Kim SH, Ahn JW, et al. 2014. Genetic diversity and relationship assessment based on AFLP analysis in blackberry (Rubus fruticosus L.) mutant lines. Plant Breed. Biotech. 2: 386-395.

Ryu JH, Kim DS, Ha BK, Kim JB, Kim SH, Jeong IY, et al. 2012. Growth characteristics and morphological variation analysis of mutant lines derived from gamma-ray and chemical mutagen treatments in Rubus fruticosus L. J. Radiat. Ind. 6: 257-265.
Skrede G, Wrolstad RE. 2002. Flavonoids from berries and grapes. p.71-133. In: G. Mazza, M.L. Maguer, J. Shi (ed.). Biochemical and processing aspects, CRC Press, Boca Raton, FL.

Slinkard K, Singleton VL. 1977. Total phenol analysis: automation and comparison with manual methods. Am. J. Enol. Viti. 28: 49-55.

Stack D. 1997. Phenolic metabolism, p.387-416. In: P.M. Dey, J.B. Harborne (ed.). Plant biochemistry. Academic Press, London.

Stintzing FC, Stintzing AS, Carle R, Wrolstad RE. 2002. A novel zwitterionic anthocyanin from evergreen blackberry (Rubus laciniatus Willd.). J. Agricult. Food Chem. 50: 396-399.

Visser T, Verhaegh JJ, De Vries D. 1971. Pre-selection of compact mutants induced by X-ray treatment in apple and pear. Euphytica 20: 195-207.

Vrhovsek U, Giongo L, Mattivi F, Viola R. 2008. A survey of ellagitannin content in raspberry and blackberry cultivars grown in Trentino (Italy). Eur. Food Res. Technol. 226: 817-824.

Wang SY, Lin HS. 2000. Antioxidant activity in fruits and leaves of blackberry, raspberry, and strawberry varies with cultivar and developmental stage. J. Agric. Food Chem. 48: 140-146.

Williner MR, Pirovani ME, Güemes DR. 2003. Ellagic acid content in strawberries of different cultivars and ripening stages J. Sci Food Agric. 83: 842-845.

Zhishen J, Mengcheng T, Jianming W. 1999. The determination of flavonoid contents in mulberry and their scavenging effects on superoxide radicals. Food Chem. 64: 555-559. 